\title{
Electrolyzed Oxidizing Water and Its Applications as Sanitation and Cleaning Agent
}

\author{
Attia $\operatorname{Iram}^{1} \cdot$ Xinmiao Wang $^{2} \cdot$ Ali Demirci $^{1}$ (i) \\ Received: 20 August 2020 / Accepted: 13 January 2021 / Published online: 19 February 2021 \\ (c) The Author(s), under exclusive licence to Springer Science+Business Media, LLC part of Springer Nature 2021
}

\begin{abstract}
Electrolyzed oxidizing water (EOW) is one of the promising novel antimicrobial agents that have recently been proposed as the alternative to conventional decontamination methods such as heat and chemical sanitizers. Acidic EOW with $\mathrm{pH}$ ranging from 2 to 5 is regarded most applicable in the antimicrobial treatment of vegetables and meats. Neutral and alkaline electrolyzed water have also been explored in few studies for their applications in the food industry. Neutral electrolyzed water is proposed to solve the problems related to the storage and corrosion effect of acidic EOW. Recently, the research focus has been shifted toward the application of slightly acidic EOW as more effective with some supplemental physical and chemical treatment methods such as ultrasound and UV radiations. The different applications of electrolyzed water range from drinking water and wastewater to food, utensil, and hard surfaces. The recent studies also conclude that electrolyzed water is more effective in suspensions as compared with the food surfaces where longer retention times are required. The commercialization of EOW instruments is not adopted frequently in many countries due to the potential corrosion problems associated with acidic electrolyzed water. This review article summarizes the EOW types and possible mechanism of action as well as highlights the most recent research studies in the field of antimicrobial applications and cleaning. Electrolyzed water can replace conventional chemical decontamination methods in the industry and household. However, more research is needed to know its actual mechanism of antimicrobial action along with the primary concerns related to EOW in the processing of different food products.
\end{abstract}

Keywords Non-thermal $\cdot$ Electrolyzed oxidizing water $\cdot$ EO water $\cdot$ EOW $\cdot$ Neutral EOW $\cdot$ Acidic EOW $\cdot$ Alkali EOW

\section{Introduction}

Food safety has become one of the most prominent challenges even in the industrialized world as more and more foodborne pathogens and outbreaks are being identified and reported. According to the most recent report by CDC, 841 cases of foodborne disease outbreaks, 48 million illnesses, and 3000 deaths per year were reported in the USA [1]. Similar statistics (23 million illnesses and 5000 deaths) are also reported for European countries [2]. Foodborne outbreaks are more prevalent in developing countries where food safety management is more difficult [3]. Food safety

Ali Demirci

demirci@psu.edu

1 Department of Agricultural and Biological Engineering, Pennsylvania State University, University Park, PA, USA

2 Department of Food Science and Biotechnology, Zhejiang Gongshang University, Hangzhou, China issues related to common and most essential food products such as milk, meats, vegetables, and fruits are still the most basic problems in both developed and developing countries [4-6]. The processing of food products for making them safe and storable for longer periods is one of the most significant goals of the food industry.

Foodborne pathogens such as Listeria monocytogenes, Salmonella Enteritidis, Escherichia coli O157: H7, and Staphylococcus aureus have been regarded as the most common pathogens related to the recent outbreaks [7]. While the prevalence of such microorganisms is greater in unprocessed foods, many mild processing methods have been adopted to increase the shelf-life of food products. The conventional processing methods include physical and chemical treatments such as heat and chlorine-based sanitizers [8]. When thermal processing is not ideal in the case of many food products which can change the product quality, the chemical sanitizers are commonly used. Some examples of such chemical sanitizers are chlorine, 
peracetic acid, and hydrogen peroxide [9]. However, the challenges associated with the chemical sanitizers include the formation of toxic chemical by-products, which are harmful to the human health and environment [10].

The problems associated with the conventional food processing methods can be solved by the novel and nonthermal treatment methods such as high hydrostatic pressure, ozone, non-thermal plasma, and power sonication. One of the most prominent novel antimicrobial treatments, in this regard, is the electrolyzed oxidizing water (EOW). The EOW is produced by the electrolysis of dilute salt solutions in such a way that the electrolysis chamber is separated in cathode and anode with the help of a diaphragm. The resulting solution can be categorized into acidic and alkaline electrolyzed water. The neutral electrolyzed water can also be formed by mixing the acidic and alkaline EWs or by using an electrolysis chamber without a diaphragm.

There are multiple applications of electrolyzed water based on its types. For example, acidic and neutral electrolyzed waters are effective in the antimicrobial properties. Alkaline electrolyzed waters are also effective in antimicrobial applications, but they have also been researched for their benefits as drinking water [11]. The research on all such applications is ongoing, and the potential of EOW for ensuring food safety is also being explored extensively. This review summarizes the recent findings in the investigation of different types of electrolyzed water as the antimicrobial agent in various food products. In addition, the review also discusses the potential mechanism of action along with the commercialization aspect of EOW. The current and future trajectory of research on this topic is also discussed with the gaps in the knowledge which are still present in the literature after almost thirty years of extensive research.

\section{Types of EOW}

The concept of cleaning and disinfecting through water electrolysis is not new. During 1970s, the major focus shifted toward the disinfection of fresh and drinking water with the help of electrolysis [12]. In 1981, the purification of wastewater by electrolysis was proposed [13]. Since 1980s, there have been many reports about the antimicrobial activity of different types of electrolyzed water in the food industry $[14,15]$. Electrolyzed water has been proved to be one of the most effective treatment methods where the damages caused by active chlorine content are minimum. EOW is being researched for different antimicrobial purposes for the past few decades and special focus has been given to its various types that can have differential effects based on their specific properties. The ambiguity in the terminology should be mentioned here as most of the research reports use different names for the same type of electrolyzed water [16]. All such names are, however, based on the same properties such as $\mathrm{pH}, \mathrm{ORP}$, and free chlorine content. A list of common names used for each type is given in Table 1 .

Electrolyzed water is generated by passing electric current ( 9-10 V electric potential) from a dilute salt solution. The most common salt used in this process is $\mathrm{NaCl}$, but a mixture of $\mathrm{KCl}$ and $\mathrm{MgCl}_{2}$ is also used [14]. The electric current is usually between 8 and 10 a [15]. There are various properties of electrolysis processes such as water flow rate, temperature, and concentration of the salt solution, which affect the final output efficiency [17]. All these properties also define the resulting properties of the generated water. According to the process of electrolysis, EOW can be divided into three main types which are acidic EOW, alkaline or basic EOW, and neutral EOW (NEW). Among all these types, acidic EOW has got the most attention due to its highly efficient antimicrobial activity principle. Alkali EOW and

Table 1 Common Nomenclature and physical properties of different types of electrolyzed oxidizing water

\begin{tabular}{|c|c|c|c|c|c|c|}
\hline Electrolyzed water type & Common names & Abbreviation & $\mathrm{pH}$ & ORP $(\mathrm{mV})$ & $\begin{array}{l}\text { Chlorine } \\
\text { content } \\
(\mathrm{mg} / \mathrm{L})\end{array}$ & References \\
\hline Acid electrolyzed water & $\begin{array}{l}\text { Acidic electrolyzed water } \\
\text { Electrolyzed oxidized water } \\
\text { strongly acidic electrolyzed } \\
\text { water } \\
\text { electrolyzed strong acid aque- } \\
\text { ous solution }\end{array}$ & $\begin{array}{l}\text { AEW } \\
\text { EO } \\
\text { EOW } \\
\text { SAEW } \\
\text { ESAAS } \\
\text { StAEW }\end{array}$ & $2-3$ & $>1000$ & $20-60$ & [23], [34], [87] \\
\hline $\begin{array}{l}\text { Slightly acidic electrolyzed } \\
\text { water }\end{array}$ & $\begin{array}{l}\text { Slightly acidic electrolyzed } \\
\text { water }\end{array}$ & SIAEW & $5.0-6.5$ & $>900$ & $10-30$ & {$[35],[48],[87]$} \\
\hline Alkaline electrolyzed water & $\begin{array}{l}\text { Alkaline electrolyzed water } \\
\text { Basic electrolyzed water } \\
\text { Electrolyzed reduced }\end{array}$ & $\begin{array}{l}\text { AlEW } \\
\text { BEW } \\
\text { ER }\end{array}$ & $10.0-11.5$ & -795 to -900 & NA & [34], [18] \\
\hline Neutral electrolyzed water & Neutral electrolyzed water & NEW & $7-8$ & 750 & 50 & {$[14],[88],[67,40]$} \\
\hline
\end{tabular}


NEW are also being researched for their efficacy in different antimicrobial applications, and other uses such as cleaning. Both acidic and alkali EOW are generated in an electrolysis chamber where the anode and cathode are separated with the help of a diaphragm. NEW can be produced in a single cell chamber without diaphragm or just mixing acidic and alkali EOW at certain ratios (Fig. 1).

Acidic EOW is produced at the anode. During electrolysis, the dissolved salt separates into negative $\left(\mathrm{Cl}^{-}\right)$and positive ions $\left(\mathrm{Na}^{+}\right)$. At the same time, hydrogen ions $\left(\mathrm{H}^{+}\right)$and hydroxyl ions $\left(\mathrm{OH}^{-}\right)$are also formed. Thus, the negatively charged ions $\left(\mathrm{Cl}^{-}\right.$and $\left.\mathrm{OH}^{-}\right)$move to anode and give up electrons and become oxygen gas $\left(\mathrm{O}_{2}\right)$ and chlorine gas $\left(\mathrm{Cl}_{2}\right)$. Other important products formed at the anode are hypochlorous acid $(\mathrm{HOCl})$, hypochlorite ions $\left(\mathrm{OCl}^{-}\right)$, and hydrochloric acid $(\mathrm{HCl})$. Here are the reactions for the formation of EOW at the anode [18]: growth of different types of microorganisms and their spores. Some theories suggest the low $\mathrm{pH}$, high oxidationreduction potential (ORP) combined with active chlorine is the main reason behind the bactericidal activities [21]. The low $\mathrm{pH}$ makes the cells more susceptible to active chlorine and as the result more $\mathrm{HOCl}$ molecules can enter through the cell membrane. Oxidation from high ORP damages cell membranes, and it has also been hypothesized that high ORP can change the normal electron flow of the cell [14]. Aside from the help from low $\mathrm{pH}$ for entering the cells, active chlorine compounds can destroy the structure of cell membranes. After entering cells, active chlorine compounds can react with the nucleic acids or destroy the key enzymes which are important for the normal metabolic functions [22]. $\mathrm{HOCl}$ is considered to be one of the most effective antimicrobial agents as it can penetrate the cells and oxidize the important metabolic compounds in the cell [14]. On the other hand, acidic EOW also has high ORP, which in turn
Fig. 1 Fig. 1. Schematic of EO water generation [18]

$$
\begin{aligned}
& 2 \mathrm{NaClCl} 2+2 \mathrm{e}-+2 \mathrm{Na}+ \\
& 2 \mathrm{H} 2 \mathrm{O} 4 \mathrm{H}++\mathrm{O} 2+4 \mathrm{e}- \\
& \mathrm{Cl} 2+\mathrm{H} 2 \mathrm{OHCl}+\mathrm{HOCl}
\end{aligned}
$$

$$
\mathrm{HOCl} \mathrm{H}++\mathrm{OCl}-
$$

The antimicrobial activity of EOW is being explored extensively in the food industry these days [19, 20]. However, the main principle for the antimicrobial activity is still under investigation. There are multiple theories as to how EOW can have strong inhibitory effects on the
Tap water Salt solution

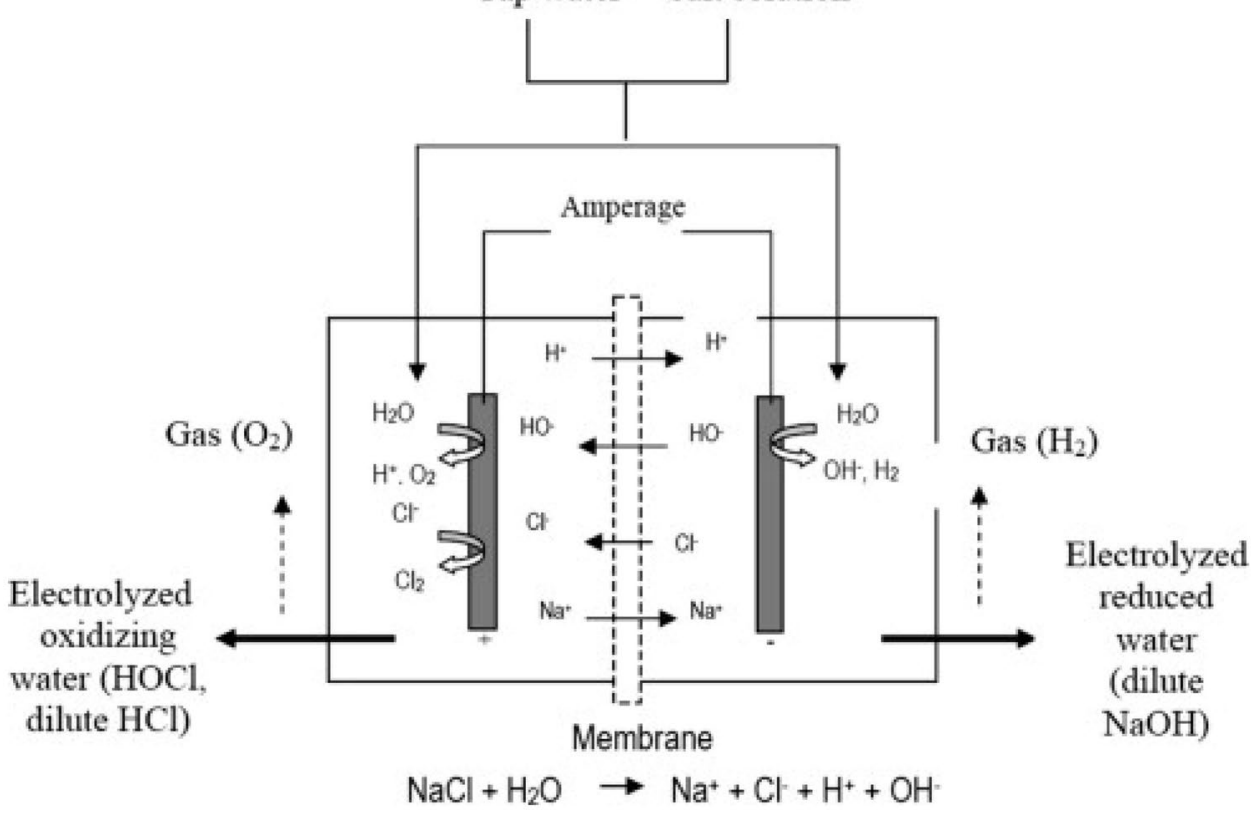

can sensitize the cell membrane [16]. The high ORP can also lead to the destruction of cell metabolism by reducing free radicals in microbial systems.

Alkali EOW is usually used as a degreaser and a mild cleaning agent before the application of effective antimicrobial agents [23]. In this regard, it is also used for cleaning the common surfaces and things that do not require harsh antimicrobial treatments. Alkali EOW is formed at the cathode of the electrolysis chamber where positive ions such as $\mathrm{H}^{+}$and $\mathrm{Na}^{+}$are moved toward the cathode where they take electrons and become hydrogen gas $\left(\mathrm{H}_{2}\right)$ or sodium hydroxide $(\mathrm{NaOH})$. The typical reactions are as follows [18]: 
$2 \mathrm{NaCl}+2 \mathrm{OH}-2 \mathrm{NaOH}+\mathrm{Cl}-$

$2 \mathrm{H} 2 \mathrm{O}+2 \mathrm{e}-2 \mathrm{OH}-+\mathrm{H} 2$

The $\mathrm{pH}$ also plays a role in the disinfection as it is greater than 11 in the case of alkali EOW water. The presence of dilute $\mathrm{NaOH}$ is linked with a high surface decontamination effect [24]. While alkali EOW can be effective for bactericidal effect, it is not as effective as acidic EOW and therefore has fewer applications for the industry and research.

Neutral EOW (NEW) is considered the least effective in antimicrobial activities among the three types of electrolyzed water. However, it is less corrosive and can enter the microbial cell without much hindrance. Therefore, it has also been explored extensively where corrosiveness is a concern. Basically, NEW is formed by electrolyzing the dilute salt solution without the addition of a diaphragm. The resulting positive and negative ions react with each other to form a nearly neutral solution $(7-8 \mathrm{pH})$ with around $800 \mathrm{mV}$ ORP. Another way to produce NEW is by mixing the EOW with $\mathrm{OH}^{-}$ions. Among various concerns related to EOW, one of the most prominent is storage which decreases the effectiveness of EOW with respect to time. NEW, on the other hand, has a longer shelf life as compared with EOW. Therefore, NEW is advantageous over EOW where long storage of water is required.

All three types of EOW are currently being explored for their effectiveness in the biological systems as the antimicrobial agents. Different applications of electrolyzed water include major types of pathogenic agents including bacteria, fungi, viruses, protozoa, algae, and nematodes [16]. However, the main mode of action of each type is different in terms of chemical reactions and the end usage. So far, acidic EOW is the most researched electrolyzed water as an antimicrobial agent and has been proven to be effective to be used on industrial scales. Figure 2 shows commercially available EO water generators.

\section{Antimicrobial Activity for Different Applications}

Electrolyzed water has been explored in different biological models such as microbial suspensions, food surfaces, food processing equipment, agriculture, hospitals, and drinking water. The varying results of the effectiveness of antimicrobial activities of electrolyzed water depend on several factors including the specified attributes of the biological system or model under observation [15]. For example, the contributing factors such as exposure time, active chlorine content (ACC), and temperature will have different effects on suspensions as compared with surfaces. Nevertheless, there are many studies that assess the effect of electrolyzed water on antimicrobial activities in different biological systems. The handling of chlorine should be with care as high concentrations can be corrosive that can trigger skin or respiratory tract irritation [9]. The reaction of $\mathrm{HOCl}$ and $\mathrm{OCl}^{-}$with the organic substances can create compounds such as trihalomethanes or chlorohydroxyfuranones. These compounds are cytotoxic and genotoxic which means they can be carcinogens to humans.

The in vitro antimicrobial activity of electrolyzed water is usually determined in terms of the microbial strains under consideration for that application [15]. For example, Fenner et al. [25] evaluated the effect of electrolyzed water on different microbial species involved in the veterinary medicine and reported that some microbial species such as Proteus mirabilis are more sensitive to electrolyzed water as compared with other microbial strains such as Pseudomonas aeruginosa. The reasons for such differences in the susceptibilities are unknown, and more research is needed to confirm the effect of different bacterial properties such as cell wall in the resistance to the action of EOW. Staphylococcus aureus was more sensitive to electrolyzed water as compared with some other bacterial species [25]. Aside from the microbial species under study, the treatment factors such as exposure time, chlorine concentration, and $\mathrm{pH}$ also played a significant role in the deactivation of microbes in the suspensions. Interestingly, a shorter exposure time was correlated positively with the reduction of viable microbial cells [26]. For example, the exposure time of $30 \mathrm{~s}$ is reported to completely inactivate the foodborne pathogens such as Listeria monocytogenes and Escherichia coli O157: H7 [27]. On the other hand, longer exposure periods of more than 3 min were correlated negatively with $\log$ reduction [26]. The effect of active chlorine concentration is also assessed in multiple research reports and more than $20 \mathrm{ppm}$ is correlated with effective inactivation [28]. Along with all such factors, the pathogens' resistance for the action of EOW has also been studied in some research papers. One example, in this regard, is the study conducted by Jadeja et al. [29]. The researchers explore the patterns of resistance by different E. coli strains [29].

The action of electrolyzed water on food surfaces such as fruits [30], vegetable [31-33], seeds [20], meat [23, 34], eggs [19], and others are also being studied extensively from the past twenty years. There are multiple reports on the action of electrolyzed water on vegetable surfaces such as cabbages [35], cilantro [33], and cucumbers [36]. While various factors such as washing time, the concentration of active chlorine species are other factors that are assessed in these reports, there are multiple reports which also contribute toward the quality of such food products after the 
Fig. 2 EO water generators [94]

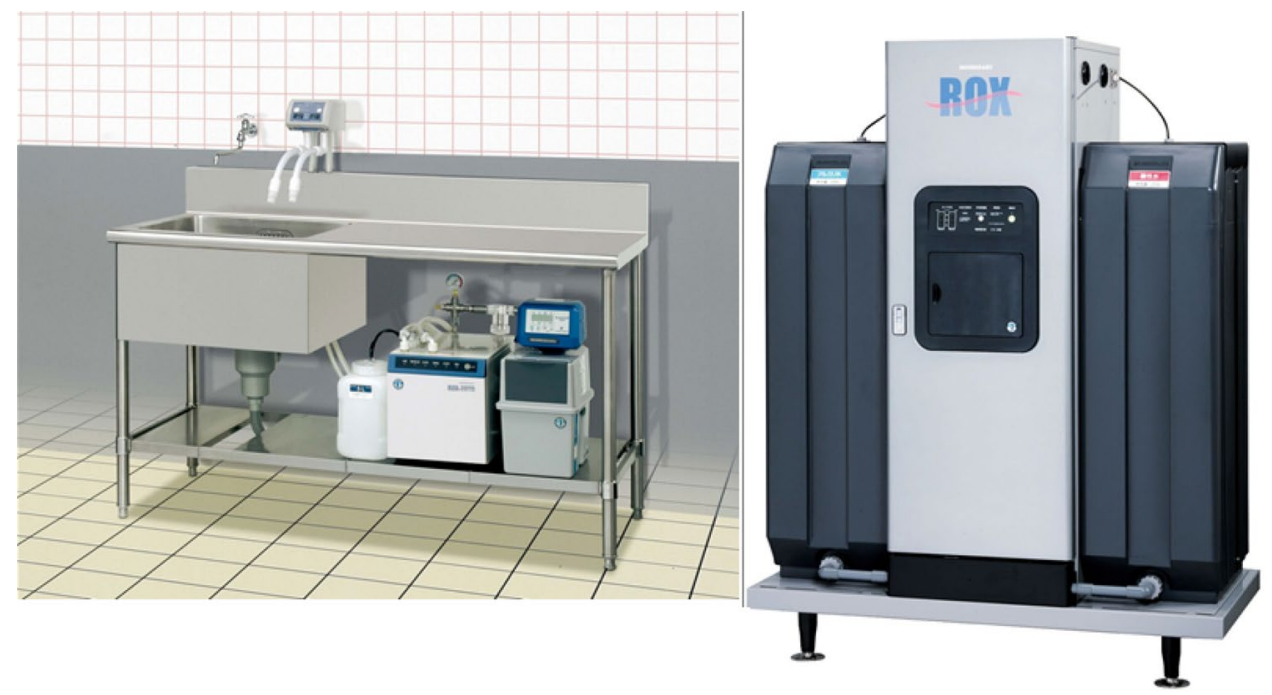

treatment with electrolyzed water $[37,38]$. There are also research reports where special methods were optimized to get the maximum antimicrobial activity without compromising the quality of the food. For example, Ozer and Demirci [34] developed a response surface model (RSM) by optimizing treatment variables such as time and temperature for the combined effect of various types of electrolyzed water on salmon fillets.

Along with the food surfaces, the potential of electrolyzed water on the cleaning and disinfection of food processing equipment surfaces has also been reported extensively. One interesting example is the research project conducted in our lab to implement the Cleaning-inPlace (CIP) practices in the milk processing system [39]. The transfer pipelines used in a milk farm need to be cleaned thoroughly and frequently, and various chemicals are being used for this purpose. However, electrolyzed water, specifically EOW, has the potential to clean the inner surfaces of the pipes without the use of harmful chemicals which are also detrimental to the environment [40]. EOW was used for CIP practice in a pilot-scale milking system, and various factors such as cleanliness and antimicrobial action of EOW were evaluated. Along with the inner surfaces of the pipes, other equipment handled in the lab has also been investigated for the action of electrolyzed water [41]. The composition of the surface under study is one of the most important factors in determining the effect of electrolyzed water on the microbial species. Therefore, the surfaces made of glass, stainless steel, and ceramic have also been evaluated [42].

The agriculture and food industry are closely related. Therefore, the practices to ensure the minimum acceptable levels of foodborne pathogens in agriculture are also being studied. The potential of using electrolyzed water to prevent crop diseases has also been explored. There are some studies that evaluated the effect of electrolyzed water on the growth of mung bean sprouts [95]. It was discovered that electrolyzed water not only helps in the reduction of pathogenic microbial species on the sprouts but also helps in the growth of the sprouts. An important dietary supplement is a gamma-Aminobutyric acid (GABA) which is shown to be increased in the brown rice by the treatment of electrolyzed water [43]. This is due to the positive correlation between sprout length and GABA production in brown rice. The growth is enhanced by the action of electrolyzed water as the growth hindering microbial species are killed.

The antimicrobial applications of electrolyzed water are not only confined to the food and agriculture industry. Hospital surfaces such as computers and diagnostic equipment are prone to be contagious from the infected patients. which can then be transmitted to hospital staff and other patients. For this purpose, the frequent sanitization of the hospital surfaces is ensured. However, the chemicals used for this purpose can be hazardous to the environment. Electrolyzed water, therefore, has been explored for its use in the hospitals [44]. Another example of the application of electrolyzed water is in wound healing [45].

Although not extensively researched, alkaline electrolyzed water and neutral electrolyzed water have also been shown to enhance the quality of drinking water. Alkaline water was used for drinking purposes in Japan for many years [46]. Alkaline electrolyzed water or electrolyzed reducing water with the $\mathrm{pH}$ near neutral or slightly above has been shown to increase the health of the digestive system. However, the research on this subject is not conducted very extensively. The effect of dietary supplements such as hydrogen in the alkaline electrolyzed water has been reported by many researchers [11, 47]. 


\section{Recent Studies on the Antimicrobial Activity for each EOW Types}

Research on the antimicrobial properties of electrolyzed water started in the medical and health industry where it was used for disinfecting surgical instruments [14]. In last 5 years, more focus has been given to neutral and slightly acidic electrolyzed water as compared with acidic and alkaline electrolyzed waters (Table 2). The main reason for this shift is effective antimicrobial properties along with the minimum effect on the quality of food products. However, the acidic and alkaline water systems are still in research focus due to their higher antimicrobial properties.

\section{Acidic Electrolyzed Water}

There have been multiple reports on the effectiveness of acidic electrolyzed water in the decontamination of food products including vegetables [32,35], meat [48], and many others. The basic principle of antimicrobial activity for acidic electrolyzed water is the combined effect of lowered
$\mathrm{pH}$ and active chlorine species, which act synergistically to alter the cell membrane structure and vital proteins. In recent years, the main focus for acidic electrolyzed water research has been on the meat products and their storage properties $[49,50]$.

One interesting application of acidic EOW has recently been established by Han et al. [51]. The biofilm formation is one of the more common problems in dealing with the foodborne pathogens, as it has been established that more than $60 \%$ of foodborne microorganisms can form biofilm [51]. Biofilm formation is problematic as a small proportion of viable cells can lead to biofilm formation and contamination of food products. Han et al. [51] showed that acidic electrolyzed water with $\mathrm{pH}$ around 2-3 can be effective against biofilm forming bacteria [52].

While the antimicrobial effect of acidic electrolyzed water is desired in many food products, there are other attributes and effects of acidic EOW that are being explored in agriculture and food industries. Some examples of such attributes are storage, enhanced nutritive, and quality properties [53]. Such attributes are under focus due to the higher antimicrobial properties of acidic EOW which in turn can compromise

Table 2 Recent reports on the antimicrobial properties of electrolyzed water based on its types

\begin{tabular}{|c|c|c|c|c|c|c|}
\hline Application & Microorganism & $\begin{array}{l}\text { Log reduction } \\
\text { (CFU/unit) }\end{array}$ & $\mathrm{pH}$ & ORP $(\mathrm{mV})$ & $\mathrm{ACC}(\mathrm{mg} / \mathrm{l})$ & Reference \\
\hline \multicolumn{7}{|c|}{ Acidic electrolyzing water } \\
\hline Salmon fillets & L. monocytogenes & 0.75 & 2.6 & 1140 & 65 & {$[50]$} \\
\hline Biofilm & E. coli & 0.7 & 2.94 & 1087 & 48.3 & {$[51]$} \\
\hline Meat & E. coli & 1.30 & 3.03 & 759.9 & 34.3 & [49] \\
\hline Fresh cut apples & Yeast & 1.86 & 2.87 & 1113 & 102 & [89] \\
\hline \multicolumn{7}{|c|}{ Slightly acidic electrolyzing water } \\
\hline Pure culture & S. aureus & 5.8 & 6.1 & 893.5 & 30 & {$[55]$} \\
\hline Celery and cilantro & Bacteria and yeast & $2.2-4.1$ & $5.76-6.05$ & $879.3-923.6$ & $25-30$ & {$[58]$} \\
\hline Squid surface & Natural microbiota & 1.46 & 6.45 & 901 & 50 & {$[57]$} \\
\hline Suspension & E. coli & 5.91 & 6.40 & 910 & 60 & {$[56]$} \\
\hline Suspension & E. coli and S. aureus & 6.02 & 6.1 & 863.5 & 30 & {$[78]$} \\
\hline Fresh fruits & E. coli and L. monocytogenes & 2.28 & 5.42 & 818 & 30 & {$[63]$} \\
\hline Suspension & S. aureus & 3.06 & 6.1 & 893.5 & 30 & [74] \\
\hline Freshwater & E coli & 1 & 5.98 & 859 & 28.7 & {$[90]$} \\
\hline \multicolumn{7}{|c|}{ Alkaline electrolyzing water } \\
\hline Wine Grapes & Yeast & 0.5 & 9 & NA & 400 & [59] \\
\hline Wine Grapes & Brettanomyces bruxellensis & 2.1 & 9 & NA & 400 & {$[60]$} \\
\hline Beefsteak & Natural microbiota & Variable & 9 & NA & 100 & [91] \\
\hline \multicolumn{7}{|c|}{ Neutral electrolyzing water } \\
\hline Suspension & Human norovirus & $5^{*}$ & 6.5 & 939.7 & 270 & {$[86]$} \\
\hline Atlantic Salmon & L. monocytogenes & 5.6 & 6.8 & 786 & 60 & {$[5]$} \\
\hline Pork products & $\begin{array}{l}\text { E. coli, Salmonella Enteritidis } \\
\text { and Yersinia enterocolitica }\end{array}$ & 0.8 & 7.64 & 818 & 74 & {$[4]$} \\
\hline Fresh cut apples & Yeast & 1.96 & 7.95 & 757 & 101 & [89] \\
\hline Lettuce & Salmonella spp. & 4 & 6.3 & $800-900$ & 50 & [92] \\
\hline
\end{tabular}


the quality and nutritive properties of food products, if suboptimal $\mathrm{pH}$ is used. The comparison of strongly and slightly acidic waters has also been conducted to evaluate the effect of such treatments on the overall food quality and bacterial $\log$ reductions [54]. All such research articles are published recently to confirm more about the acidic electrolyzed water which has also already been established as one of the most prominent antimicrobial treatments.

\section{Slightly Acidic Electrolyzed Water}

Slightly acidic electrolyzed water has been proposed to help the issues created by the strongly electrolyzed water treatment such as corrosiveness and low $\mathrm{pH}$. The low $\mathrm{pH}$ contributes toward the rapid volatilization of dissolved chlorine gas that has adverse effects on human health [26]. To reduce all such negative aspects of strongly acidic electrolyzed water, the slightly acidic electrolyzed water is proposed. As mentioned earlier, this type of electrolyzed water has $\mathrm{pH}$ range from 5 to 6.5 and ACC from 10 to $30 \mathrm{mg} / \mathrm{L}$. However, there are research articles where the term "slightly acidic" is used beyond these ranges $[55,56]$.

While different principles have been proposed for the action of acidic electrolyzed water, it is interesting to know that recent reports show that SlAEW have higher antimicrobial activities as compared with EOW (Table 2). This can be due to the fact that low $\mathrm{pH}$ can increase the loss of chlorine gas by volatilization and thus decreasing the antimicrobial activity. Different reports show that the antimicrobial activity of SIAEW in terms of log reduction falls from 1 to $6 \mathrm{CFU} / \mathrm{ml}$ or $\mathrm{CFU} / \mathrm{g}$ as compared with the EOW which has been shown to reduce the microbial colonies by $1 \mathrm{CFU} / \mathrm{ml}$ or $\mathrm{CFU} / \mathrm{g}$. The time and temperature are some of the important factors which have been evaluated in this regard as well. In addition, the storage of the water for later use or the storage of food product in the water is also a concern [57].

Regardless, there are several research articles published recently which show the strong antimicrobial effect of SlAEW. Some examples are given in Table 2. Most of such research setups used pure cultures of pathogenic microbes to evaluate the effect of SIAEW on the deactivation of such microbes. Some research projects were based on specific food products and their storage conditions. One example is the use of SIAEW ice to store squid [55]. Other examples are of celery and cilantro surfaces and the antimicrobial activity on the bacteria and yeast is evaluated [58].

\section{Alkaline Electrolyzed Water}

Alkaline electrolyzed water is not as frequently explored as compared with the different concentrations of acidic electrolyzed water (Table 2). Nevertheless, there are few recent studies, which show the effect of high $\mathrm{pH}$ in the electrolyzed water for the cleaning of food products. One application of such type of water (high $\mathrm{pH}$ ) is shown by Cravero et al. [59] on wine grapes. The antimicrobial effect of yeast species on the wine grapes is evaluated, while the $\mathrm{pH}$ of the treatment was around 9. The same type of water was also used to deactivate Brettanomyces. ruxellensis on wine grapes and 2.1 CFU/ml log reduction has been reported [60].

\section{Neutral Electrolyzed Water}

NEW has recently gained attention due to its potential in solving problems of low $\mathrm{pH}$ and possible corrosion in electrolyzed water treatment (Table 2). Meat products such as Atlantic salmon and pork products have been evaluated by treating them with NEW $[4,5]$. In case of Atlantic salmon, NEW with $6.8 \mathrm{pH}$ showed the $\log$ reduction of $5.6 \mathrm{CFU} /$ $\mathrm{ml}$ for L. monocytogenes. The pork products, however, only showed $0.8 \mathrm{CFU} / \mathrm{ml} \log$ reduction for different foodborne bacterial species [4]. This shows the variable effect of NEW for different microbial species. Nevertheless, it can be seen that NEW has higher antimicrobial properties as compared with strong acidic and alkaline electrolyzed water.

An important advantage of NEW over EOW is its unchanged antimicrobial activity after storage. Cui et al. [61] compared different attributes such as $\mathrm{pH}, \mathrm{ACC}$, ORP, and antimicrobial activities of NEW and EOW before and after storage under different conditions. They showed that while most of these attributes changed after storage for both NEW and EOW, the antimicrobial properties of NEW remains unchanged [61], while the antimicrobial activity of acidic EOW decreased significantly after storage [61]. This shows the potential of storage capability of NEW as compared with that of acidic EOW.

\section{Synergistic Effect of Electrolyzed Water with Other Antimicrobials}

There are many antimicrobial treatments that are being utilized in the food industry based on their disinfection properties and non-corrosive attributes. While electrolyzed water is ideal for antimicrobial properties, it has various limitations such as corrosiveness and storage capabilities. Therefore, recently, a shift in the research has been conducted to utilize electrolyzed water with some other antimicrobial treatment. The combination of two or more antimicrobial treatments can help in the optimization of the treatment parameters in such a way that minimum change in the quality can happen with maximum disinfection properties.

Among various combinations of antimicrobial treatments with electrolyzed water, ultrasound, ultraviolet light, and heat 
treatments are some of the most common methods (Table 3 ). The use of chlorine products in the disinfection process is prohibited in many European countries due to the formation of harmful byproducts that are harmful to both environment and human health. $\mathrm{HOCl}$ in the electrolyzed water is the main antimicrobial agent and has been speculated in multiple studies to be an effective antimicrobial agent in the food industry. To minimize the side effects created by chlorine present in the electrolyzed water, SlAEW is combined with ultrasound in various research setups. Ultrasound is effective in reducing the dipping time that is needed for the effective disinfection of food surfaces. For example, Luo and Oh [62] investigated the combined effect of SIAEW and ultrasound on the overall antimicrobial effect and dipping time of freshcut bell peppers in the electrolyzed water. They optimized that the antimicrobial process in such a way that only $1 \mathrm{~min}$ of dipping time was enough to reduce by $3 \log \mathrm{CFU} / \mathrm{g}$.

While ultrasound has been shown to be effective as a supplementary treatment with electrolyzed water in many other research setups, other physical parameters such as mild heat have also been used in this regard. However, it is crucial to note that such physical parameters can have detrimental effects on the quality of food products. Therefore, their optimization to achieve tolerable quality changes is extremely necessary. Luo and Oh [62] also used mild heat treatments in addition to electrolyzed water and ultrasound. They concluded that bell peppers can be treated in mild heat $\left(60{ }^{\circ} \mathrm{C}\right)$. The mild heat enhanced the antimicrobial properties of electrolyzed water. Another physical treatment is the use of microbubble technique [63]. Such technology is employed with the help of ultrasonication, and the principle is to enhance the exposure time of electrolyzed water with the help of waves of ultrasound.

Chemical treatments such as calcium oxide and fumaric acid are also being utilized along with the slightly acidic electrolyzed water to enhance the antimicrobial properties of such treatments [63]. The synergetic effects of such combined treatments can also ensure food quality. Such technologies are being researched greatly on the fruits and vegetable surfaces. The main reason is the minimum effect of physical and mild chemical treatments. Although heat is another candidate in this regard, it can potentially damage the food quality and optimization of such parameters is required.

Among various research projects where mild heat is used as an additional treatment along with electrolyzed water, the research report by Ovissipour et al. [5] is particularly interesting because of the food product. They worked on the surface of the Atlantic salmon. The meat products especially seafood are not ideal food products to be treated through heat or electrolyzed water as such treatments can destroy the protein structure and thus compromising the quality of the food product. However, Ovissipour et al. [5] showed that NEW can be a very good antimicrobial treatment option in the case of Atlantic salmon as it does not destroy the protein secondary structure of salmon. They also showed that higher temperatures can help in increasing the action of NEW and thus increasing the efficiency of this antimicrobial treatment. All such treatment combinations can provide the optimum conditions for the antimicrobial activities in the food industry with minimal processing time.

\section{Cleaning of Equipment Surfaces and Cleaning-In-Place for Food Processing Equipment}

In addition to the cleaning and sanitation of food product surfaces, there have also been studies using EOW on the cleaning of food processing equipment surfaces; milking system is a particularly representative example. Conventionally, on a dairy farm, milk is collected from the cows using milk claws then transferred to the storage tank via transfer pipelines. The pipelines are connected from teats to the milk claws and then to the storage tank. In the storage tank, the milk is stored at $4{ }^{\circ} \mathrm{C}$. When milking is finished, all milk-contact surfaces are contaminated, i.e., soiled, with milk and needs to be immediately cleaned and sanitized in an appropriate manner. Cleaning-in-place (CIP) has been applied in large-size dairy farms to shorten the time of dissembling processing lines and equipment for cleaning and
Table 3 Recent reports on the combination of antimicrobial treatments with electrolyzed water

\begin{tabular}{llll}
\hline Year & Electrolyzed water Type & Other treatment & Reference \\
\hline 2016 & SlAEW & Ultrasound and mild heat & {$[62]$} \\
2017 & SlAEW & Ultrasound & {$[74]$} \\
2017 & Acidic EOW & Ultraviolet light or/and ultrasounds & {$[50]$} \\
2017 & SlAEW & Combination of physical and chemical & {$[63]$} \\
& & treatments & {$[93]$} \\
2018 & Acidic EOW and NEW & Ultraviolet-C (UV-C) radiation & {$[5]$} \\
2018 & Acidic EOW and NEW & Mild thermal processing & {$[89]$} \\
\hline
\end{tabular}


depending on the type of target contaminants to be removed; the specific procedures differ. In milking system CIP, the process starts with a tepid/warm water rinse, followed by a high temperature, alkaline wash to remove the organic deposits such as proteins and an intermediate water rinse, and ends with an acid wash to remove mineral deposits; prior to the next milking, a sanitizing cycle is usually circulated within the system pipelines to ensure the safety of the milkcontact surfaces (Table 4), as suggested by Dairy Practices Council [64]. There is also a novel one-step CIP which combines the alkaline wash and acidic wash cycles into one, with claimed comparable CIP performance, to save water and chemical usage as well as energy expenditure [65].

Based on the above-mentioned study conducted by Walker et al. [41] using EOW on specimens of different materials, and taking into consideration of the similarity in wash solution properties used in conventional milking system CIP and EOW, a pilot study was firstly conducted in author's lab on a 27-m in length laboratory scale milking system for EOW CIP feasibility test, and an optimal condition of $70^{\circ} \mathrm{C}$ alkaline wash, $45^{\circ} \mathrm{C}$ acid wash with a CIP duration of 10 min was achieved with a $100 \%$ cleaning and disinfection of milk contact surfaces [39]. Followed by this inspiring result, a 4-month trial using EOW was conducted on a $140-\mathrm{m}$ tie stall dairy barn in the real world [66]. Results also showed that EO water CIP performance, compared to conventional CIP using harsh chemicals, was comparably good or even better. What is more, is that the operational cost of EO water CIP was reduced about $25 \%$ with economic benefit. From this, an optimal condition of near-neutral EW on pilot milking system one-step CIP (60\% acidic EW with a starting temperature of $59^{\circ} \mathrm{C}$ and a cleaning duration of $17 \mathrm{~min}$ ) was also demonstrated of the capability in achieving a 100\% CIP performance with lowered operational cost [67]. Similar investigations on milk storage tank $(15 \mathrm{~L}$ in volume and equipped with $360^{\circ}$ static spray ball) using alkaline and acidic EOW [68], stainless steel disks in acidic EOW with varying ACC concentrations [69], stainless steel chips using acidic EOW [70], iron materials used in a disinfection channel using slightly acidic EOW [71], milking system specimens such as stainless steel, rubber and PVC using alkaline EOW [72], stainless steel and tile specimens soiled with food allergens (peanut, soy, fish, wheat, tree nut, dairy, eggs and shrimp) using alkaline EOW [73], and etc., had also been conducted to demonstrate the efficacy of electrolyzed oxidizing water on equipment surfaces and surface specimens.

The most difficult to be cleaned parts in the pipelines are turning elbows, dead corners, etc. Such parts can deposit both organic matter and microbial biofilms. The improvement of the cleaning and disinfection performance includes to alter or increase the chemicals used, to increase the CIP solution temperature in some cases, or to increase the hydrodynamic forces the CIP fluids exert on the soil and deposits. There have been efforts made to extract processing parameters and develop mathematical models of the cleaning and disinfection process, in an effort to find the optimal CIP conditions and reduce expenditure. The function of a chemical solution during CIP is to react with the soil and deposit; this results in a decrease in adhesion force between soil and surfaces, improving a better removal of the deposits. From this point of view, higher concentration of CIP chemicals leads to a better cleanliness of the equipment and pipeline surfaces. The adhesive strength between the deposit and the surface depends on the type and amount of the deposits, as well as the surface material and surface property. Longer deposit settling time (and sometimes higher temperature causing a denaturation of organic materials) will also increase the adhesive strength, and the difficulty to clean. For any deposit (or soil particles), when the lift force is higher than the adhesive force, the removal process dominates; otherwise, particles will gradually settle down and forming deposits. Different particle motions will also lead to different deposit removal kinetics [38, 96-99] which exceeds the scope of this review.

There are several factors that need to be taken into consideration to improve the performance of CIP. The first is to include a higher degree of fluid profile complexity, such as to introduce higher flow velocity (turbulence) at the entrance $[100,101]$, or insert one or several swirling pipelines in the middle of straight pipelines [74, 102], or adding pulsated air into fluid to form "slugs" [66]. All these approaches aim to break the static flow patterns and enhance CIP performance. The second is the type and usage of CIP chemicals. With target deposit properties, the optimal types and concentrations could be applied to reach the highest cleanliness while maintaining a low cost of chemical expenditure and acceptable chemical residue after CIP. The
Table 4 CIP procedures recommended by the Dairy Practices Council [64]

\begin{tabular}{ll}
\hline CIP cycle & Specific requirement \\
\hline Warm water rinse & 2 min, $43.3-48.9^{\circ} \mathrm{C}$ \\
Alkaline wash & $8-10 \mathrm{~min} ;$ start: $71.1-76.7^{\circ} \mathrm{C}$; finish: $48.9^{\circ} \mathrm{C} ; \mathrm{pH}>12.0 ;$ \\
& $120 \mathrm{ppm}$ chlorine; $1100 \mathrm{ppm}$ alkalinity; $>20$ slugs \\
Acid rinse & $3-5$ min, pH about 3.0 \\
Sanitize & Environmental Protection Agency $(\mathrm{EPA})$ registered dairy sanitizer \\
\hline
\end{tabular}


third factor is related to the kinetics of chemical reactions, which is temperature. Higher temperature will accelerate chemical reactions, but during milking system CIP, high temperature will also cause a denaturation of whey protein, sticking to the contact surfaces and making it more difficult to clean; on the other hand, if the solution temperature is too low, saturated fat in milk tend to crystallize and solidify, which is adverse to a cleaner CIP performance.

Bird and Fryer [106] started to investigate how proteinaceous deposits are removed under controlled solution temperature, flow rate, and chemical concentration and tried to establish the kinetics of deposit removal with experimental data and mathematical modeling. Graßhoff [107] further proposed a three-stage cleaning procedure during alkaline washing, including a deposit swelling stage, during which deposit swells and forms high void fraction matrix, a uniform erosion stage with shear and diffusion, and a decay stage dominated by shear and mass transport. A further quantitative illustration of the cleaning kinetics of milking heat exchanger were proposed by Dürr and Graßhoff [104], where the fraction of the remaining deposit, $r(t)$, at affecting time $t$ can be expressed as:

$r(t)=\exp \left[-(t / T)^{R}\right]$

where the time constant $T$ is the time to reduce remaining deposit to 0.368 , or to reach $63.2 \%$ deposit removal. $R$ is the slope when using a " $\lg \lg (1 / r)$ " vs " $\lg t$ " plot. Based on this model, Dürr [103] further showed that a two-parameter Weibull distribution could be used to better describe the cleaning process, where the cleaning parameters can be interpreted as "life-time distribution of the soil subjected to a specified cleaning procedure."

[40] and [105] also conducted experimentally based CIP modeling on a pilot-scale milking system. The "surface evaluation simulator" used real milk, instead of the previous protein solutions or other "simulated" milk, as the deposit soil, and considered a complete milking system CIP process including the warm water rinse cycle, the alkaline wash cycle, and the following acid rinse cycle. Stainless steel pipes of $152.4 \mathrm{~mm}$ in length were used as test specimens, and inserted in the "upstream" and "downstream" of the milking system pipelines (Fig. 3). The specimens along with the pipelines were soiled first [39] and undergone CIP with gradual sampling time points in warm water rinse, alkaline wash, and acid wash cycles. The residual deposits on the specimens were weighed and normalized before fit into a unified overall first order deposit removal model. Validation of the developed model was further conducted at $2 \mathrm{~s}$ during the warm water rinse cycle, $165 \mathrm{~s}$ during the alkaline wash cycle, and 765 s during the acid wash cycle, respectively. Experimental results showed that the first cycle, warm water rinse alone, could remove more than $90 \%$ of the initial soiled deposit, indicating a significant importance of a timely rinse after milking. With the developed two-term exponential model, the deposit removal process was described as a loosely bound bulk deposited removed quickly at the beginning of the cycle and a continuous, constant removal of tightly bound granule deposit removal throughout the entire CIP cycle (Fig. 4). With this developed deposit removal model, authors were also able to reduce the CIP process from the original 20.5 to $9.17 \mathrm{~min}$, with satisfactory CIP performance, confirmed by ATP bioluminescence test validation. In a similar manner [67], also developed and validated deposit removal models for blended EO water milking system CIP.

In addition to the environmental benefit of EO water CIP, there is also a reduction in the operational cost. When using EO water solutions, the cost is mainly comprised of the salt and water to generate EO water solutions and the salt to soften supply water (reducing hardness), as well as the electricity usage of both heating and mechanical equipment consumption. Similarly, if using conventional CIP, the chemicals for each CIP cycle take a great proportion of the cost spent. Wang et al. [66] had shown that on the commercial dairy farm, one complete EO water CIP needs $\$ 2.15$, while one complete conventional chemical CIP costs $\$ 2.84$, a $25 \%$ reduction in operational cost could be achieved using EO water CIP. This difference in cost was further expanded when comparing blended EO water CIP with commercial one-step CIP on a lab-scale pilot milking system. The operational cost using the blended EO water CIP at its optimal condition was $\$ 0.55$; on the other hand, when using commercial onestep CIP at the chemical concentration suggested by the manufacturers, the operational cost was calculated as $\$ 2.82$, more than five times higher [67].

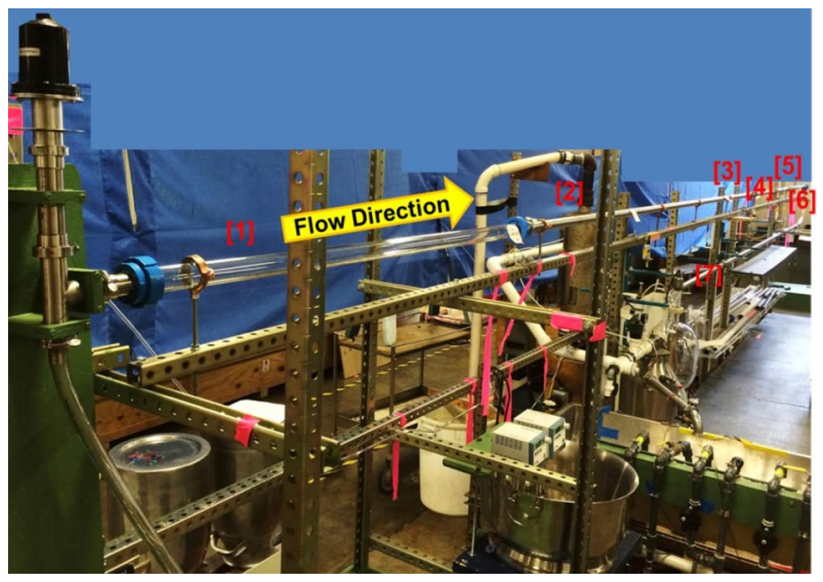

Fig. 3 Stainless steel surface evaluation simulator with specimen of 152.4-mm straight pipe test section [40] 


\section{Research Trajectory in the History of Electrolyzed Water}

Research on the antimicrobial properties of saline water after electrolysis started early in the 1960s [75]. Electrolyzed water was shown to have disinfecting properties for surgical instruments and surgeons' hands. The research interests were then focused on the application of electrolysis in treating the water itself (Fig. 5). There were many studies where the quality of water after the germicidal treatment of electrolysis is discussed. Some examples include the germicidal effect in the drinking water, while others discuss the treatment of wastewater by electrolysis [76], [13].

One of the earliest uses of electrolyzed water was for the decontamination of surgical instruments, and it was reported in Russia [14]. However, Japan has been one of the leading countries in making electrolyzed water generators for both antimicrobial purposes and drinking water applications. There are commercial portable electrolyzed water generators that can be used for household uses [49]. The therapeutic properties of alkaline water are not as much researched as the antimicrobial properties of acidic and slightly acidic electrolyzed waters. However, it is discussed that alkaline electrolyzed water is effective in treating the problems of the digestive system [11].

The most prominent usage of electrolyzed water is as an antimicrobial agent in agriculture, food, and many other industries where disinfection is a requirement for consumer products. Since 1987, a large number of articles have been published discussing the effect of different types of electrolyzed water in the decontamination of food products ranging from vegetables and fruits to meat [77], [15]. The special focus has always been the acidic electrolyzed water which is more prominent in its germicidal action as compared with alkaline and neutral electrolyzed water. The main reason for such focus is the low $\mathrm{pH}$ and high availability of the active chlorine species which can react with the enzymes and cell membrane to destroy the microbial cells.

In recent years, a concern toward the active species of chlorine in the acidic electrolyzed water and the formation of the byproducts has been shown [38]. To solve such problems associated with acidic electrolyzed water, neutral and slightly acidic electrolyzed waters are proposed. Such types of electrolyzed water have shown the longer storage capability without losing the antimicrobial properties as it was the case with acidic electrolyzed water. The comparison of different types of electrolyzed waters has shown that some types are better in the antimicrobial properties while others can retain the quality of food products more efficiently [5].

In the recent years, the research focus on the electrolyzed water has been shifted toward two major goals: determination of the mechanism of antimicrobial treatment through electrolyzed water $[55,78]$ and comparison of different types of electrolyzed waters to know which can be used for which food product. The primary concern about the usage of electrolyzed water in the meat industry has also been discussed [38]. It is discussed that strong acidic electrolyzed water can change the protein secondary structure in the meat [5]. For this purpose, slightly acidic or neutral electrolyzed water is

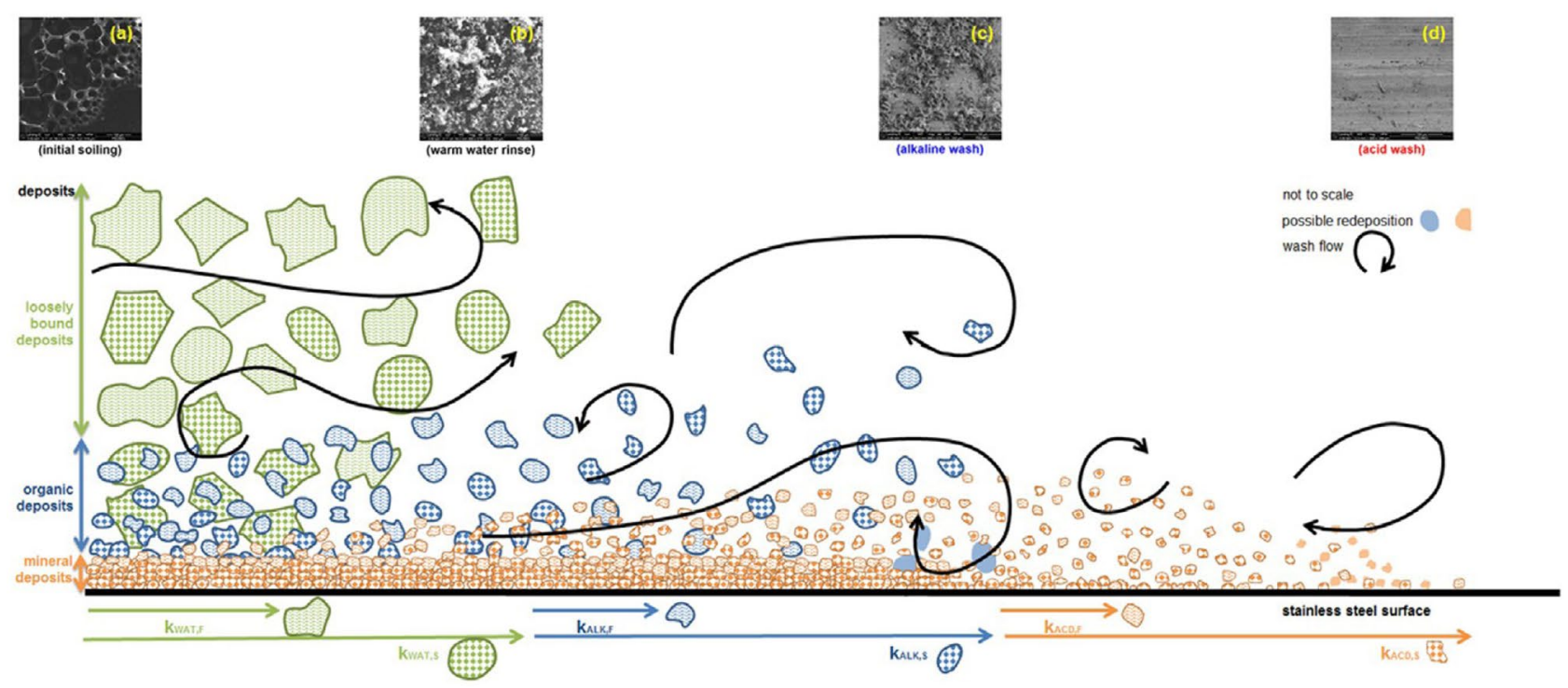

Fig. 4 Illustration of the deposit removal process during warm water rinse, EO water alkaline wash, and EO water acid wash cycles, in the vicinity of the milk deposit contact surface of stainless steel [40] 


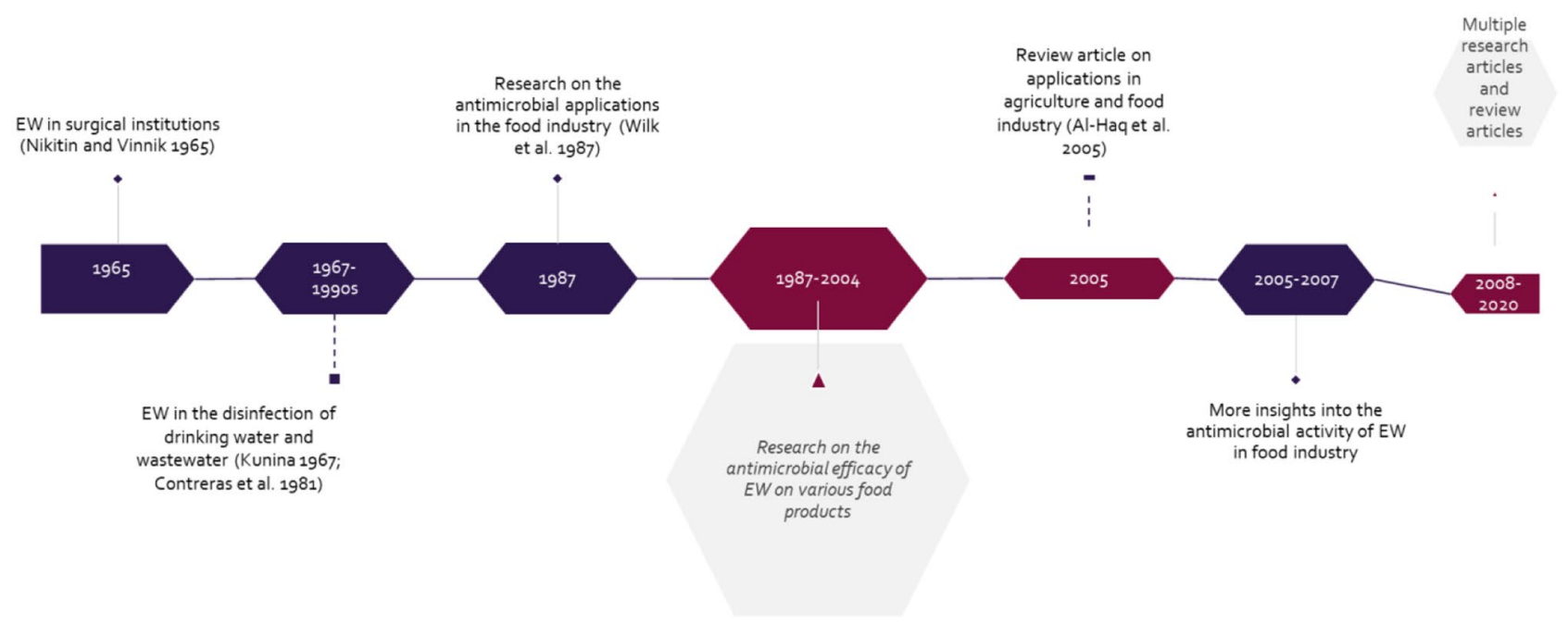

Fig. 5 Research trajectory in the field of EW as the antimicrobial agent

proposed. On the other hand, the quality of vegetables and fruits is not as much affected by the treatment of electrolyzed water. There are many research articles that discuss the efficiency of all types of electrolyzed water in the treatment of vegetables and fruits. Overall, electrolyzed water can be accepted as a potential antimicrobial agent in the food industry.

\section{Commercialization of Electrolyzed Water}

The antimicrobial activity of electrolyzed water has been a common topic of research in many countries including China, Korea, and USA (Fig. 6). However, the commercialization of the electrolyzed water is not adopted on the same scale. Due to the availability of a large number of research publications that show the effectiveness of electrolyzed water in the antimicrobial treatment of food products, the commercialization of electrolyzed water generators is getting more interest in the electronic industry [15]. There are many companies that are now trying to design an electrolyzed water generator that can be used for both research purposes and commercialized for general consumption. For example, companies such as Envirolite® [79], RVD Corporation [80], Hoshizaki Electric Co. Ltd [40], EcoLogic Solutions Inc. [81], and Viking pure ${ }^{\mathrm{TM}}$ are making electrolyzed water generators which are being used in the research laboratories and commercialization for household usage is being encouraged by these companies. The most common problem in the usage of electrolyzed water in the household is the production of harmful and toxic byproducts. However, the companies claim that their technology does not lead to the formation of harmful chlorine species [15].
The commercialization of EW in the USA has been a slow process due to the underlying concerns about the potential corrosion of electrolyzed water. However, new efforts are being employed to help to not only commercialize the production of EW in the domestic use but to use it in the CIP processes. One example is the research project by EAU Technologies Inc. The company established the research project to help in the industrial use of electrolyzed water in CIP practices. The project was established in 2009, and the electrolyzed water was commercialized under the name of Empowered Water ${ }^{\mathrm{TM}}$ [15].

The usage of electrolyzed water as the antimicrobial agent in the meat industry is prohibited in European countries [15]. The main reason is the inactivation of protein molecules by electrolyzed water. On the other hand, the electrolyzed water technology is being used in drinking water disinfection [11]. However, the USA is taking initiatives in the usage of electrolyzed water in the cleaning and sanitizing of various food products [82]. The usage of electrolyzed water as the chlorine reagent has been approved in the production of organic material in 2015 [82]. Among various advantages of electrolyzed water, financial viability is one of the most commonly considered factors. The onsite production, dilution, and waste management of electrolyzed water make it very applicable in different industries.

In addition to the industrial and household applications of electrolyzed water, other sectors of the food industry such as restaurants are also getting benefits from electrolyzed water cleaning [83]. The duration of cleaning is decreased dramatically with the usage of electrolyzed water instead of simple tap water, and the countertops can also be disinfected with this water. It is not harmful to human contact if the water does not go into the eyes or is not ingested. All such 
Fig. 6 Research articles published by the countries from 2010 to 2020 on the topic of electrolyzed water and its application in different food products

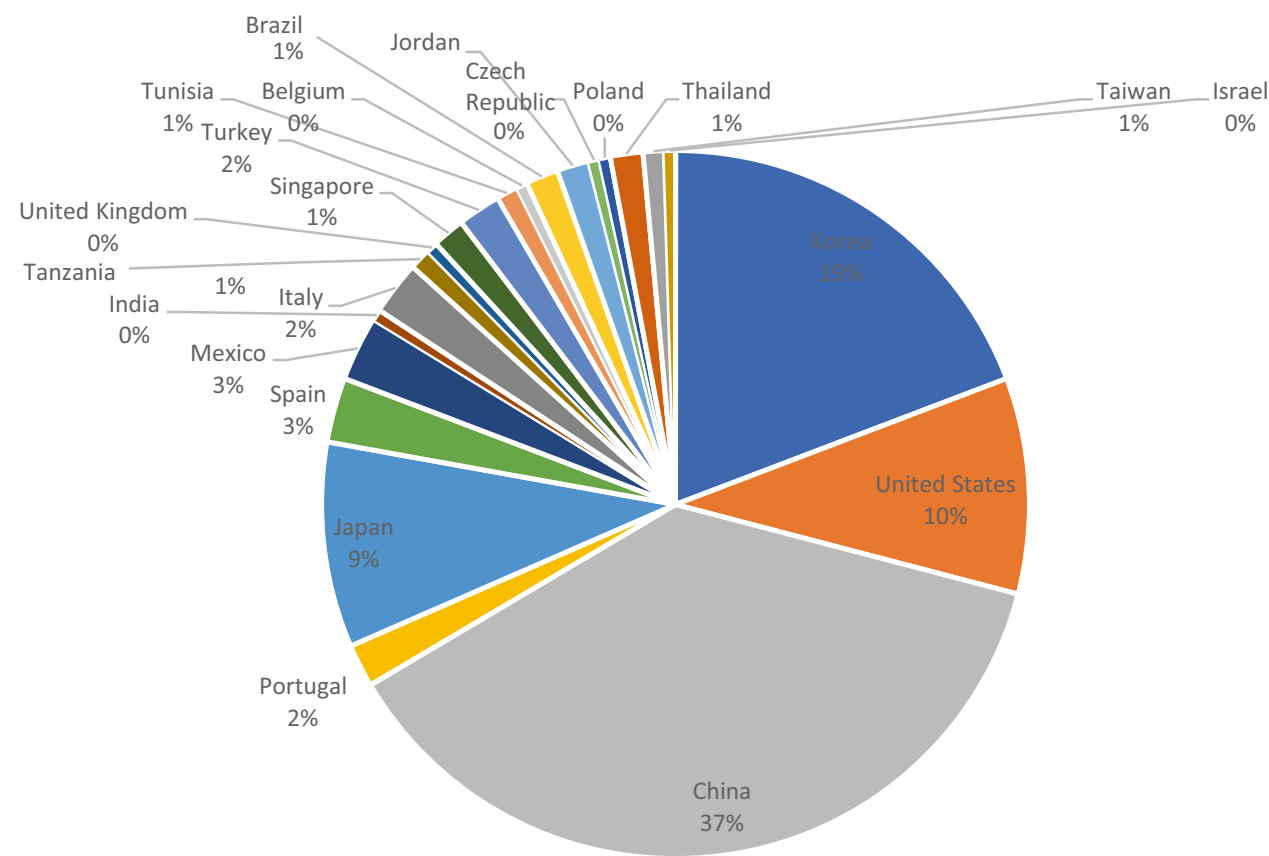

applications increase the probability of the commercialization of electrolyzed water.

\section{Future Trends in the Research and Commercialization of Electrolyzed Water}

Among various future trends in the research of electrolyzed water, the most important one perhaps would be the mechanism of antimicrobial action. While many theories including the synergistic effect of low $\mathrm{pH}$, high ORP, and active chlorine species are proposed in the literature, the actual mechanism of action has not yet been confirmed [55]. In addition, the synergistic effect of low $\mathrm{pH}$ and active chlorine species can only be true for acidic electrolyzed water. In this regard, the mechanism of antimicrobial action of neutral and slightly acidic electrolyzed water is also of interest as it has been shown that such types of electrolyzed water can be more effective than acidic electrolyzed water for some food products. The main advantage of using neutral and slightly acidic electrolyzed water is storage capability. It has been shown that acidic electrolyzed water can lose its antimicrobial properties if stored for longer periods. The neutral electrolyzed water does not have that disadvantage.

The second topic of interest in the future should be the investigation of the concerns related to the use of electrolyzed water in meat products [38]. There are research studies that show that acidic electrolyzed water can change the secondary structure of the protein in meat products which can affect the quality of these food products [5]. In addition to meat products, the quality of vegetables and fruits after the treatment of electrolyzed water should also be investigated. Although there are many research articles that deal with the quality characteristics of such products, but the mechanism of the effect of EW on the quality of the food products should be determined for each product [33].

The commercialization of EW as the disinfecting agent is a slow process in the food industry. Many different antimicrobial treatment methods including heating and chemical sanitizers are in trend for different food products. However, thermal processing has always retained a challenge in the meat and raw food industry where the quality of the food can be greatly affected by high temperatures. For such reasons, non-thermal processing methods are gaining interest in food quality research and commercialization. Another necessity in the processing of the food products is the on-site and inexpensive production of the chemical sanitizers. The chemical sanitizer currently being used does not show such characteristics. Therefore, the commercialization of electrolyzed water generation systems can be expected in the near future.

Electrolyzed water has been shown to be effective against common human viruses such as hepatitis B virus (HBV) and HCV [84], and human immunodeficiency virus (HIV) [85]. The disinfection of surfaces with the help of acidic electrolyzed water has been proposed in many research articles [86]. Therefore, there might be a possibility that electrolyzed water can be efficient in decreasing the exposure time in the case of novel coronavirus (COVID-19). The feasibility of electrolyzed water in destroying the various virus structures has been 
discussed in the literature reports, and there should be research about its effect on COVID-19.

\section{Conclusion}

Electrolyzed water is an emerging antimicrobial treatment method that has recently gained interest due to its confirmed applications in the food industry. It has also been shown that the action of EW is greater in the suspensions as compared with the food and equipment surfaces. Regardless of its different levels of effectiveness in suspensions versus surfaces, EW can be considered as one of the effective non-thermal processing techniques for the food industry. Electrolyzed water has many types, and different uses of each type are specified and researched in recent years. For example, acidic and slightly acidic electrolyzed waters are recommended as the antimicrobial agents, while alkaline $\mathrm{EW}$ is better for drinking water purposes. In addition, the disadvantages presented by acidic electrolyzed water can be solved by using neutral electrolyzed water. The recent research reports also show the combination of different physical and chemical treatment methods with electrolyzed water to get the maximum antimicrobial effect without compromising the quality of the food products. The commercialization of the instruments for the onsite production of electrolyzed water has recently been proposed by various companies. However, commercialization is slow in European countries as compared with Asian countries and the USA.

Funding This study was funded in-part by FULBRIGHT Student Program and USDA National Institute of Food and Agriculture Federal Appropriations under Project PEN04594 and Accession number 1007291.

\section{Declarations}

Conflict of Interest The authors declare that they have no conflict of interest.

Ethical Approval This article does not contain any studies with human participants or animals performed by any of the authors.

\section{References}

1. CDC (2020) Estimates of foodborne illness in the United States. https://www.cdc.gov/foodborneburden/index.html

2. WHO (2020) The burden of foodborne diseases in the who European region. https://www.euro.who.int/_data/assets/pdf_ file/0005/402989/50607-WHO-Food-Safety-publicationV4_ Web.pdf

3. WHO (2015) WHO estimates of the global burden of foodborne diseases. https://apps.who.int/iris/bitstream/handle/10665/ 199350/9789241565165_eng.pdf?sequence $=1$
4. Han D, Hung Y-C, Wang L (2018) Evaluation of the antimicrobial efficacy of neutral electrolyzed water on pork products and the formation of viable but nonculturable (VBNC) pathogens. Food Microbiol 73:227-236

5. Ovissipour M, Shiroodi SG, Rasco B et al (2018) Electrolyzed water and mild-thermal processing of Atlantic salmon (Salmo salar): reduction of Listeria monocytogenes and changes in protein structure. Int J Food Microbiol 276:10-19

6. Singhal P, Kaushik G, Hussain CM, Chel A (2020) Food safety issues associated with milk: a review. In: Safety issues in beverage production. Elsevier, pp 399-427

7. Cho TJ, Kim NH, Kim SA et al (2016) Survival of foodborne pathogens (Escherichia coli O157: H7, Salmonella Typhimurium, Staphylococcus aureus, Listeria monocytogenes, and Vibrio parahaemolyticus) in raw ready-to-eat crab marinated in soy sauce. Int J Food Microbiol 238:50-55

8. Gouma M, Álvarez I, Condón S, Gayán E (2020) Pasteurization of carrot juice by combining UV-C and mild heat: Impact on shelf-life and quality compared to conventional thermal treatment. Innov Food Sci Emerg Technol 102362

9. de São José JFB, Vanetti MCD (2015) Application of ultrasound and chemical sanitizers to watercress, parsley and strawberry: microbiological and physicochemical quality. LWT-Food Sci Technol 63:946-952

10. Allende A, Tomas-Barberan FA, Gil MI (2006) Minimal processing for healthy traditional foods. Trends Food Sci Technol 17:513-519

11. Xue J, Shang G, Tanaka Y et al (2014) Dose-dependent inhibition of gastric injury by hydrogen in alkaline electrolyzed drinking water. BMC Complement Altern Med 14:81

12. Eibl V, Reis A (1976) Method of disinfecting water

13. Contreras S, Pieber M, Toha J (1981) Purification of wastewater by electrolysis. Biotechnol Bioeng 23:1881-1887

14. Hricova D, Stephan R, Zweifel C (2008) Electrolyzed water and its application in the food industry. J Food Prot 71:1934-1947

15. Rahman SME, Khan I, Oh D (2016) Electrolyzed water as a novel sanitizer in the food industry: current trends and future perspectives. Compr Rev Food Sci Food Saf 15:471-490

16. Al-Haq MI, Sugiyama J, Isobe S (2005) Applications of electrolyzed water in agriculture \& food industries. Food Sci Technol Res 11:135-150

17. Hsu S-Y (2003) Effects of water flow rate, salt concentration and water temperature on efficiency of an electrolyzed oxidizing water generator. J Food Eng 60:469-473

18. Huang Y-R, Hung Y-C, Hsu S-Y et al (2008) Application of electrolyzed water in the food industry. Food Control 19:329-345

19. Bialka KL, Demirci A, Knabel SJ et al (2004) Efficacy of electrolyzed oxidizing water for the microbial safety and quality of eggs. Poult Sci 83:2071-2078

20. Sharma RR, Demirci A (2003) Treatment of Escherichia coli O157: H7 inoculated alfalfa seeds and sprouts with electrolyzed oxidizing water. Int J Food Microbiol 86:231-237

21. Park H, Hung Y-C, Chung D (2004) Effects of chlorine and pH on efficacy of electrolyzed water for inactivating Escherichia coli O157: $\mathrm{H} 7$ and Listeria monocytogenes. Int J Food Microbiol 91:13-18

22. Kim C, Hung Y-C, Brackett RE (2000a) Roles of oxidationreduction potential in electrolyzed oxidizing and chemically modified water for the inactivation of food-related pathogens. $\mathbf{J}$ Food Prot 63:19-24

23. Fabrizio KA, Sharma RR, Demirci A, Cutter CN (2002) Comparison of electrolyzed oxidizing water with various antimicrobial interventions to reduce Salmonella species on poultry. Poult Sci 81:1598-1605 
24. Kikuchi K (2000) Cathodic reaction of water electrolysis. In: Abst. 7th Annual Meeting Functional Water Symp., 2000. pp $16-17$

25. Fenner DC, Bürge B, Kayser HP, Wittenbrink MM (2006) The anti-microbial activity of electrolysed oxidizing water against microorganisms relevant in veterinary medicine. J Vet Med Ser B 53:133-137

26. Rahman SME, Ding T, Oh D-H (2010) Effectiveness of low concentration electrolyzed water to inactivate foodborne pathogens under different environmental conditions. Int J Food Microbiol 139:147-153

27. Kim C, Hung Y-C, Brackett RE (2000b) Efficacy of electrolyzed oxidizing (EO) and chemically modified water on different types of foodborne pathogens. Int J Food Microbiol 61:199-207

28. Quan Y, Choi K-D, Chung D, Shin I-S (2010) Evaluation of bactericidal activity of weakly acidic electrolyzed water (WAEW) against Vibrio vulnificus and Vibrio parahaemolyticus. Int J Food Microbiol 136:255-260

29. Jadeja R, Hung Y-C, Bosilevac JM (2013) Resistance of various shiga toxin-producing Escherichia coli to electrolyzed oxidizing water. Food Control 30:580-584

30. Ding T, Ge Z, Shi J et al (2015) Impact of slightly acidic electrolyzed water (SAEW) and ultrasound on microbial loads and quality of fresh fruits. LWT-food Sci Technol 60:1195-1199

31. Izumi H (1999) Electrolyzed water as a disinfectant for fresh-cut vegetables. J Food Sci 64:536-539

32. Koseki S, Yoshida K, Isobe S, Itoh K (2001) Decontamination of lettuce using acidic electrolyzed water. J Food Prot 64:652-658

33. Wang H, Feng H, Luo Y (2004) Microbial reduction and storage quality of fresh-cut cilantro washed with acidic electrolyzed water and aqueous ozone. Food Res Int 37:949-956

34. Ozer NP, Demirci A (2006) Electrolyzed oxidizing water treatment for decontamination of raw salmon inoculated with Escherichia coli O157: $\mathrm{H} 7$ and Listeria monocytogenes Scott A and response surface modeling. J Food Eng 72:234-241

35. Koide S, Takeda J, Shi J et al (2009) Disinfection efficacy of slightly acidic electrolyzed water on fresh cut cabbage. Food Control 20:294-297

36. Koseki S, Yoshida K, Isobe S, Itoh K (2004) Efficacy of acidic electrolyzed water for microbial decontamination of cucumbers and strawberries. J Food Prot 67:1247-1251

37. Aday MS (2016) Application of electrolyzed water for improving postharvest quality of mushroom. LWT-Food Sci Technol 68:44-51

38. Wang H, Duan D, Wu Z et al (2019) Primary concerns regarding the application of electrolyzed water in the meat industry. Food Control 95:50-56

39. Dev SRS, Demirci A, Graves RE, Puri VM (2014) Optimization and modeling of an electrolyzed oxidizing water based cleanin-place technique for farm milking systems using a pilot-scale milking system. J Food Eng 135:1-10

40. Wang X, Puri VM, Demirci A, Graves RE (2016a) Mathematical modeling and cycle time reduction of deposit removal from stainless steel pipeline during cleaning-in-place of milking system with electrolyzed oxidizing water. J Food Eng 170:144-159

41. Walker SP, Demirci A, Graves RE et al (2005) Response surface modelling for cleaning and disinfecting materials used in milking systems with electrolysed oxidizing water. Int $\mathbf{J}$ dairy Technol 58:65-73

42. Park H, Hung Y-C, Kim C (2002) Effectiveness of electrolyzed water as a sanitizer for treating different surfaces. J Food Prot 65:1276-1280

43. Liu R, He X, Shi J et al (2013) The effect of electrolyzed water on decontamination, germination and $\gamma$-aminobutyric acid accumulation of brown rice. Food Control 33:1-5
44. Vorobjeva NV, Vorobjeva LI, Khodjaev EY (2004) The bactericidal effects of electrolyzed oxidizing water on bacterial strains involved in hospital infections. Artif Organs 28:590-592

45. Yahagi N, Kono M, Kitahara M et al (2000) Effect of electrolyzed water on wound healing. Artif Organs 24:984-987

46. Koseki M, Tanaka Y, Noguchi H, Nishikawa T (2007) Effect of $\mathrm{pH}$ on the taste of alkaline electrolyzed water. J Food Sci 72:S298-S302

47. Fujita R, Tanaka Y, Saihara Y et al (2011) Effect of molecular hydrogen saturated alkaline electrolyzed water on disuse muscle atrophy in gastrocnemius muscle. J Physiol Anthropol 30:195-201

48. Cao W, Zhu ZW, Shi ZX et al (2009) Efficiency of slightly acidic electrolyzed water for inactivation of Salmonella enteritidis and its contaminated shell eggs. Int J Food Microbiol 130:88-93

49. Arya R, Bryant M, Degala HL et al (2018) Effectiveness of a low-cost household electrolyzed water generator in reducing the populations of Escherichia coli K12 on inoculated beef, chevon, and pork surfaces. J food Process Preserv 42:e13636

50. Mikš-Krajnik M, Feng LXJ, Bang WS, Yuk H-G (2017) Inactivation of Listeria monocytogenes and natural microbiota on raw salmon fillets using acidic electrolyzed water, ultraviolet light or/ and ultrasounds. Food Control 74:54-60

51. Han Q, Song X, Zhang Z et al (2017) Removal of foodborne pathogen biofilms by acidic electrolyzed water. Front Microbiol 8:988

52. Hu H, Cai L, Dong Y et al (2019) Modeling the degradation of acidic electrolyzed water and its ability to disinfect a dual-species biofilm. LWT 104:159-164

53. Chen Y, Xie H, Tang J, et al (2020) Effects of acidic electrolyzed water treatment on storability, quality attributes and nutritive properties of longan fruit during storage. Food Chem 126641

54. Hao J, Wu T, Li H, Liu H (2017) Differences of bactericidal efficacy on Escherichia coli, Staphylococcus aureus, and Bacillus subtilis of slightly and strongly acidic electrolyzed water. Food Bioprocess Technol 10:155-164

55. Ding T, Xuan X-T, Li J et al (2016) Disinfection efficacy and mechanism of slightly acidic electrolyzed water on Staphylococcus aureus in pure culture. Food Control 60:505-510

56. Ye Z, Wang S, Chen T et al (2017) Inactivation mechanism of escherichia coli induced by slightly acidic electrolyzed water. Sci Rep 7:1-10

57. Xuan X-T, Fan Y-F, Ling J-G et al (2017) Preservation of squid by slightly acidic electrolyzed water ice. Food Control 73:1483-1489

58. Zhang C, Cao W, Hung Y-C, Li B (2016) Disinfection effect of slightly acidic electrolyzed water on celery and cilantro. Food Control 69:147-152

59. Cravero F, Englezos V, Torchio F et al (2016) Post-harvest control of wine-grape mycobiota using electrolyzed water. Innov Food Sci Emerg Technol 35:21-28

60. Cravero F, Englezos V, Rantsiou K et al (2018) Control of Brettanomyces bruxellensis on wine grapes by post-harvest treatments with electrolyzed water, ozonated water and gaseous ozone. Innov Food Sci Emerg Technol 47:309-316

61. Cui X, Shang Y, Shi Z et al (2009) Physicochemical properties and bactericidal efficiency of neutral and acidic electrolyzed water under different storage conditions. J Food Eng 91:582-586

62. Luo K, Oh D-H (2016) Inactivation kinetics of Listeria monocytogenes and Salmonella enterica serovar Typhimurium on fresh-cut bell pepper treated with slightly acidic electrolyzed water combined with ultrasound and mild heat. Food Microbiol 53:165-171

63. Tango CN, Khan I, Kounkeu P-FN et al (2017) Slightly acidic electrolyzed water combined with chemical and physical treatments to decontaminate bacteria on fresh fruits. Food Microbiol 67:97-105 
64. DPC (2010) Guidelines for installation, cleaning, and sanitizing of large and multiple receiver parlor milking systems.

65. DeLaval.com (2020) Acid detergents in milking system. https:// www.delaval.com/en-us/our-solutions/milking/consumables/acid/

66. Wang X, Dev SRS, Demirci A et al (2013) Electrolyzed oxidizing water for cleaning-in-place of on-farm milking systems-performance evaluation and assessment. Appl Eng Agric 29:717-726

67. Wang X, Demirci A, Puri VM, Graves RE (2016) Evaluation of blended electrolyzed oxidizing water-based cleaning-in-place (CIP) technique using a laboratory-scale milking system. Trans ASABE 59:359-370

68. Yu Y (2014) Evaluation of electrolyzed water for clean-in-place of dairy processing equipment

69. Zhang C, Li B, Jadeja R, Hung Y (2016) Effects of electrolyzed oxidizing water on inactivation of Bacillus subtilis and Bacillus cereus spores in suspension and on carriers. J Food Sci 81:M144-M149

70. Quan Y, Kim H-Y, Shin I-S (2017) Bactericidal activity of strong acidic hypochlorous water against Escherichia coli O157: H7 and Listeria monocytogenes in biofilms attached to stainless steel. Food Sci Biotechnol 26:841-846

71. Yitian Z, Baoming L, Zhengxiang S et al (2017) Inactivation efficiency of slightly acidic electrolyzed water against microbes on facility surfaces in a disinfection channel. Int J Agric Biol Eng 10:23-30

72. Liu Y, Wang C, Shi Z, Li B (2019) Cleaning and bacteria removal in milking systems by alkaline electrolyzed oxidizing water with response surface design. Trans ASABE 62:1251-1258

73. Marino D (2016) Evaluation of the properties of electrochemically activated water on different salt compositions and its capabilities as an antimicrobial, cleaning, and allergen control solution

74. Li J, Ding T, Liao X et al (2017) Synergetic effects of ultrasound and slightly acidic electrolyzed water against Staphylococcus aureus evaluated by flow cytometry and electron microscopy. Ultrason Sonochem 38:711-719

75. Nikitin BA, Vinnik LA (1965) Presurgical preparation of surgeons' hands with the products of electrolysis of a 3per cent solution of sodium chloride. Khirurgiia (Sofiia) 41:104-105

76. Kunina LA (1967) From experience in the electrolytic decontamination of drinking water. Gig Sanit 32:100

77. Wilk IJ, Altmann RS, Berg JD (1987) Antimicrobial activity of electrolyzed saline solutions. Sci Total Environ 63:191-197

78. Liao X, Xuan X, Li J et al (2017) Bactericidal action of slightly acidic electrolyzed water against Escherichia coli and Staphylococcus aureus via multiple cell targets. Food Control 79:380-385

79. Yanik K, Karadag A, Unal N et al (2015) An investigation into the in-vitro effectiveness of electrolyzed water against various microorganisms. Int J Clin Exp Med 8:11463

80. Mansur AR, Oh D-H (2015) Combined effects of thermosonication and slightly acidic electrolyzed water on the microbial quality and shelf life extension of fresh-cut kale during refrigeration storage. Food Microbiol 51:154-162

81. Ding T (2019) Future trends of electrolyzed water. In: Electrolyzed water in food: fundamentals and applications. Springer, pp 269-272

82. USDA (2015) Electrolyzed water. https://www.ams.usda.gov/sites/ default/files/NOP-PM-15-4-ElectrolyzedWater.pdf

83. Tango CN, Hussain MS, Oh D-H (2019) Application of electrolyzed water on environment sterilization. In: Electrolyzed water in food: fundamentals and applications. Springer, pp 177-204

84. Sakurai Y, Nakatsu M, Sato Y, Sato K (2003) Endoscope contamination from $\mathrm{HBV}$-and $\mathrm{HCV}$-positive patients and evaluation of a cleaning/disinfecting method using strongly acidic electrolyzed water. Dig Endosc 15:19-24
85. Kitano J, Kohno T, Sano K et al (2003) A novel electrolyzed sodium chloride solution for the disinfection for dried HIV-1. Bull Osaka Med Coll 48:29-36

86. Moorman E, Montazeri N, Jaykus L-A (2017) Efficacy of neutral electrolyzed water for inactivation of human norovirus. Appl Environ Microbiol 83:e0653-e717

87. Issa-Zacharia A, Kamitani Y, Miwa N et al (2011) Application of slightly acidic electrolyzed water as a potential non-thermal food sanitizer for decontamination of fresh ready-to-eat vegetables and sprouts. Food Control 22:601-607

88. Abadias M, Usall J, Oliveira M et al (2008) Efficacy of neutral electrolyzed water (NEW) for reducing microbial contamination on minimally-processed vegetables. Int J Food Microbiol 123:151-158

89. Graça A, Santo D, Pires-Cabral P, Quintas C (2020) The effect of $\mathrm{UV}-\mathrm{C}$ and electrolyzed water on yeasts on fresh-cut apple at $4^{\circ} \mathrm{C}$. J Food Eng 110034

90. Wang S, Bao W, Zhang F et al (2018) Disinfection kinetics of slightly acidic electrolyzed water to freshwater under the condition of dynamic hybrid. J Clean Prod 174:1136-1146

91. Botta C, Ferrocino I, Cavallero MC et al (2018) Potentially active spoilage bacteria community during the storage of vacuum packaged beefsteaks treated with aqueous ozone and electrolyzed water. Int J Food Microbiol 266:337-345

92. Cap M, Rojas D, Fernandez M, et al (2020) Effectiveness of short exposure times to electrolyzed water in reducing Salmonella spp and Imidacloprid in lettuce. LWT 109496

93. Santo D, Graça A, Nunes C, Quintas C (2018) Escherichia coli and Cronobacter sakazakii in 'Tommy Atkins' minimally processed mangos: Survival, growth and effect of UV-C and electrolyzed water. Food Microbiol 70:49-54

94. Demirci A, Bialka KL (2011) Electrolyzed oxidizing water. Nonthermal processing technologies for food, 366-376

95. Rui L, Jianxiong H, Haijie L, Lite L (2011) Application of electrolyzed functional water on producing mung bean sprouts. Food Control 22:1311-1315

96. Soltani Mehdi, Ahmadi Goodarz (1994) On particle adhesion and removal mechanisms in turbulent flows. J Adhes Sci Tech 8:763-785

97. Thornton Colin, Ning Zemin (1998) A theoretical model for the stick/bounce behaviour of adhesive, elastic-plastic spheres. Powder Technol 99:154-162

98. Kuruneru Sahan Trushad Wickramasooriya, Sauret Emilie, Saha Suvash Chandra, Gu YuanTong (2016) Numerical investigation of the temporal evolution of particulate fouling in metal foams for air-cooled heat exchangers. Appl Energy 184:531-547

99. Tong Zi-Xiang, Li Ming-Jia, He Ya-Ling, Tan Hou-Zhang (2017) Simulation of real time particle deposition and removal processes on tubes by coupled numerical method. Appl Energy $185: 2181-2193$

100. Majoor FA (2003) Cleaning in place. In: Lelieveld H, Mostert M, Holah J, White B (eds) Hygiene in Food Processing. Woodhead Publishing, Cambridge, UK

101. Friis A, Jensen BBB (2016) The hygienic design of closed equipment. In: Lelieveld H, Holah J, Gabric D (eds) Handbook of Hygiene Control in the Food Industry. Woodhead Publishing, Duxford, UK

102. Li G, Hall P, Miles $\mathrm{N}, \mathrm{Wu} \mathrm{T}$ (2015) Improving the efficiency of 'Clean-In-Place' procedures using a four-lobed swirl pipe: A numerical investigation. Comput Fluids 108:116-128

103. Dürr H. (2002) Milk heat exchanger cleaning. Food and Bioproducts Processing 80:253-259

104. Graßhoff A, Dürr H (1999) Milk heat exchanger cleaning: modelling of deposit removal. Food Bioprod Process 77(2):253-259 
105. Wang X, Puri VM, Demirci A, Graves RE (2016) One-Step cleaning-in-place for milking systems and mathematical modeling for deposit removal from stainless steel pipeline using blended electrolyzed oxidizing water. Trans ASABE 59(6):1893-1904

106. Bird MR, Fryer PJ (1991) An experimental study of the cleaning of surfaces fouled by whey proteins. Food Bioprod Process 69:13-21
107. Graßhoff A (1997) Cleaning of heat treatment equipment: Fouling and Cleaning in heat treatment equipment, IDF Monograph, $32-44$

Publisher's Note Springer Nature remains neutral with regard to jurisdictional claims in published maps and institutional affiliations. 